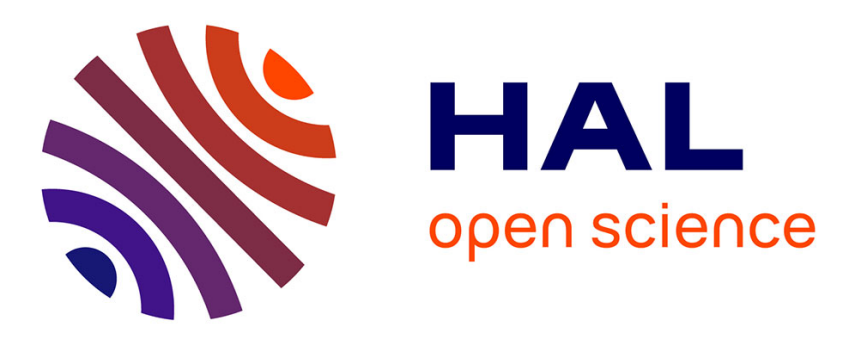

\title{
Volume relaxation in a borosilicate glass hot compressed by three different methods
}

Linfeng Ding, Karan Doss, Yongjian Yang, Kuo-Hao Lee, Michal Bockowski, Sylvie Demouchy, Manuel Thieme, Benedikt Ziebarth, Qingwei Wang, Morten

M Smedskjaer, et al.

\section{To cite this version:}

Linfeng Ding, Karan Doss, Yongjian Yang, Kuo-Hao Lee, Michal Bockowski, et al.. Volume relaxation in a borosilicate glass hot compressed by three different methods. Journal of the American Ceramic Society, 2020, 10.1111/JACE.17482 . hal-02951482

\section{HAL Id: hal-02951482 \\ https://hal.science/hal-02951482}

Submitted on 29 Sep 2020

HAL is a multi-disciplinary open access archive for the deposit and dissemination of scientific research documents, whether they are published or not. The documents may come from teaching and research institutions in France or abroad, or from public or private research centers.
L'archive ouverte pluridisciplinaire HAL, est destinée au dépôt et à la diffusion de documents scientifiques de niveau recherche, publiés ou non, émanant des établissements d'enseignement et de recherche français ou étrangers, des laboratoires publics ou privés. 
DR LINFENG DING (0rcid ID : 0000-0002-1447-5598)

DR MORTEN SMEDSKJAER (0rcid ID : 0000-0003-0476-2021)

DR JOHN C. MAURO (Orcid ID : 0000-0002-4319-3530)

Article type : Article

\title{
Volume relaxation in a borosilicate glass hot compressed by three different methods
}

Linfeng Ding ${ }^{1,2}$, Karan Doss², Yongjian Yang ${ }^{2}$, Kuo-Hao Lee ${ }^{2}$, Michal Bockowski ${ }^{3}$, Sylvie

Demouchy $^{4}$, Manuel Thieme ${ }^{4}$, Benedikt Ziebarth ${ }^{5}$, Qingwei Wang ${ }^{1 *}$, Morten M. Smedskjaer ${ }^{6}$ and John C. Mauro ${ }^{2 *}$

${ }^{1}$ State Key Laboratory for Modification of Chemical Fibers and Polymer Materials, Donghua University, Shanghai 201620, China

${ }^{2}$ Department of Materials Science and Engineering, The Pennsylvania State University, University

$$
\text { Park, PA 16802, USA }
$$

${ }^{3}$ Institute of High-Pressure Physics, Polish Academy of Sciences, Warsaw, Poland

Geosciences Montpellier, CNRS \& Université de Montpellier, Montpellier, 34095, France

${ }^{5}$ Schott AG, Corporate Research \& Development, Mainz 55122, Germany

${ }^{6}$ Department of Chemistry and Bioscience, Aalborg University, Aalborg DK-9220, Denmark

*Corresponding author: jcm426@psu.edu,wqwq888@dhu.edu.cn

\begin{abstract}
This article has been accepted for publication and undergone full peer review but has not been through the copyediting, typesetting, pagination and proofreading process, which may lead to differences between this version and the Version of Record. Please cite this article as doi: 10.1111/JACE.17482
\end{abstract}

This article is protected by copyright. All rights reserved 
The temperature dependence of glass relaxation has been intensively studied; however, the effect of an imposed pressure history on relaxation behavior is poorly understood. In this study, we subjected SCHOTT N-BK $7{ }^{\circledR}$ borosilicate glasses to isostatic compression in a Paterson press (PP) and a gas pressure chamber (GPC). The pressure ranged from $0.1 \mathrm{GPa}$ to $2 \mathrm{GPa}$ for various dwell temperatures and times near the glass transition region. Comparison with our recent results on the same glass using the piston-cylinder apparatus (PC, 0.5-1.5 GPa) reveals that the density of a glass, which has been quenched from the equilibrium state under high pressure at $2 \mathrm{~K} / \mathrm{min}$ (pressure quench), increases approximately linearly with increasing pressure up to $2 \mathrm{GPa}$. Considering the volume recovery results at ambient pressure, we assert that the preceding high-pressure treatment in PC (uniaxial loading) generates a similar isostatic pressure effect on N-BK7 glass as those of PP and GPC treatments. Finally, we verify the previously proposed two-internal-parameter relaxation model on the volume recovery data using the three different compression methods. With a new set of parameters in the model, we can account for the pressure and temperature dependence of volume relaxation even for the samples quenched from nonequilibrium states at high pressure.

Keywords: borosilicate glass; densification; volume relaxation; fictive pressure; fictive temperature

This article is protected by copyright. All rights reserved 


\section{Introduction}

Supercooled liquids and glasses show intriguing universal behavior, such as glass transition and relaxation, whose origins remain poorly understood in many systems. ${ }^{1,2}$ The temperature and thermal history dependence of glass relaxation ${ }^{3}$ has been intensively studied; however, the effect of an imposed pressure history on relaxation behavior is not well studied ${ }^{4}$. Moreover, the relaxation of silicate melts/glasses under high pressure is a key parameter to understand the geological formation of the earth (pressure increases approximately $0.3 \mathrm{GPa}$ for every $10 \mathrm{~km}$ depth), since magmas and lavas are silicate-rich melts resulting from partial melting of the Earth's mantle. 5, 6, 7

Permanent densification of glass has been observed at elevated pressures via $\operatorname{hot}^{8,9,10,11,12,13,14}$ and cold ${ }^{15}$ compression. The compression treatment can be performed using different high pressure apparatuses, e.g., gas pressure vessels (up to $\sim 2 \mathrm{GPa}$ ) ${ }^{10,11,16}$, piston-cylinder apparatus (up to $\sim 4$ $\mathrm{GPa})^{17}$, multi anvil apparatus (above $\left.5 \mathrm{GPa}\right)^{18}$, etc. During hot compression, glass samples are typically heated to the glass transition range under high pressure and then quenched to ambient pressure. This leads to permanent densification of the glass (i.e., the glass remains densified unless it is heated close to the glass transition region at ambient pressure), which also manifests itself in macroscopic properties changes such as an increase in indentation hardness ${ }^{19,20,21}$. However, the understanding of volume relaxation mechanism of a permanently densified glass is still lacking.

In our previous studies, we evaluated the pressure dependence of volume relaxation ${ }^{22}$ and viscosity ${ }^{23}$ of a commercial borosilicate glass (SCHOTT N-BK $7^{\circledR}$ ) near the glass transition region via hot compression in a piston-cylinder apparatus and in situ deformation in the Paterson press ${ }^{16}$. We introduced a two-internal-parameter (fictive temperature $T_{\mathrm{f}}$ and fictive pressure $P_{\mathrm{f}}$ ) model ${ }^{22}$ based on Gupta's approach ${ }^{24}$ and the Tool-Narayanaswamy model ${ }^{25,} 26$. Our model can explain the experimental volume relaxation data reasonably well. Results from ex situ volume relaxation and in situ viscosity measurements show a consistent change from those two different pressure sources. ${ }^{23}$ However, a true isostatic high pressure environment around the glass sample is still challenging during a hot compression treatment, especially for the piston-cylinder apparatus which subjects the glass to a uniaxial loading condition.

SCHOTT N-BK $7^{\circledR}$ is available in large formats with high homogeneity and has already been used in several studies $27,28,29,30$ as a reference material. Therefore, in this work, we perform isostatic 
hot compression experiments on SCHOTT N-BK7 ${ }^{\circledR}$ glass in the Paterson press (0.1-0.3 GPa) and a gas pressure chamber $(1-2 \mathrm{GPa})$ and then compare the results to our recent data ${ }^{22}$ from the pistoncylinder apparatus (0.5-1.5 GPa) in a uniaxial loading condition. We aim here to quantify the volume relaxation behavior of this glass.

\section{Experimental section}

The SCHOTT N-BK7 ${ }^{\circledR}$ (chemical composition ${ }^{31}$ : $74.5 \mathrm{~mol} \% \mathrm{SiO}_{2}, 10.2 \mathrm{~mol} \% \mathrm{~B}_{2} \mathrm{O}_{3}, 10.2 \mathrm{~mol} \%$ $\mathrm{Na}_{2} \mathrm{O}, 5.1 \mathrm{~mol} \% \mathrm{~K}_{2} \mathrm{O}$ and small amounts of $\mathrm{CaO}$ and $\mathrm{BaO}$ ) glass samples were machined to cylinders and mirror-polished prior to the high-pressure treatments. To minimize the density measurement uncertainty, all the samples with the maximum allowable volume were used, which was $10.00 \pm 0.05$ $\mathrm{mm}$ (diameter) $\times 17.00 \pm 0.10 \mathrm{~mm}$ (height) and $7.00 \pm 0.05 \mathrm{~mm} \times 8.00 \pm 0.05 \mathrm{~mm}$ for the Paterson press experiments (PP, University of Montpellier) and the gas pressure chamber experiments (GPC, Polish Academy of Sciences, Warsaw), respectively. The samples for the piston cylinder apparatus (PC, University of Mainz) experiments ${ }^{22}$ were machined to $7.40 \pm 0.02 \mathrm{~mm} \times 6.00 \pm 0.02 \mathrm{~mm}$. The density of N-BK7 glass at room temperature and ambient pressure is around $2.508 \pm 0.001 \mathrm{~g} / \mathrm{cm}^{3}$. The glass transition temperature $T_{g}=561{ }^{\circ} \mathrm{C}$ is defined as the temperature at which the logarithmic viscosity is $12 \log _{10}(\mathrm{~Pa} \cdot \mathrm{s}) \cdot{ }^{23}$

The full description of PP is given in Ref. 13. It is mostly used as a in situ deformation or static compression gas-medium apparatus with a routine ${ }^{25,26}$ confining pressure of $0.3 \mathrm{GPa}$. Nevertheless, we briefly recall the main experimental setup details below. A single glass sample was encapsulated with zirconia and alumina cylinders and alumina spacers inside a thin copper jacket. ${ }^{23}$ The hot compression experiments in PP were conducted with argon as the pressure medium. Temperature was

fixed at $700{ }^{\circ} \mathrm{C}$ using an internal and recalibrated furnace, and the confining isostatic pressure was maintained constant at $0.1,0.2$ or $0.3 \mathrm{GPa}$ for $2 \mathrm{~h}$. The description of GPC can be found in several recent studies $8,11,19$. Two glass samples were placed inside a graphite furnace in a vertical stack, which was separated by a $2 \mathrm{~mm}$ alumina disk, and subjected to an isostatic high-pressure treatment using nitrogen as a pressure. The hot compression experiments in GPC were conducted between $560{ }^{\circ} \mathrm{C}$ and $700{ }^{\circ} \mathrm{C}$ under a pressure of $1 \mathrm{GPa}$ or $2 \mathrm{GPa}$ for 0.5 or $2 \mathrm{~h}$ to evaluate the influence from both pressures and temperatures. The PC is self-assembled with an improved design ${ }^{32}$ based on the 
principle of Boyd and England ${ }^{17}$ with uniaxial pressure up to $3 \mathrm{GPa}$. All the PC experiments from our recent study ${ }^{22}$ were conducted in a customized pressure-cell with $\mathrm{NaCl}$ salt as the pressure transmitting medium at $700{ }^{\circ} \mathrm{C}$ under $0.5-1.5 \mathrm{GPa}$ for $24 \mathrm{~h}$ to ensure an equilibrium state for N-BK7 glass. All the hot compression experiments were followed by a controlled cooling step to room temperature at a constant rate of $2 \mathrm{~K} / \mathrm{min}$ (pressure quench). Finally, all the systems were decompressed at a rate of $10-30 \mathrm{MPa} / \mathrm{min}$ to ambient pressure.

The density of samples was measured by the Archimedes principle after the hot compression treatments. Each density measurement was repeated five times to obtain a standard deviation as the measurement uncertainty. Volume recovery measurements were conducted in the DIL 806 optical dilatometer (TA Instruments) for the samples from PP, which is the same method as the results from PC, and the TMA Q400 (TA Instruments) for the samples from GPC. The temperature of these two dilatometers had been calibrated with an uncertainty of less than $1{ }^{\circ} \mathrm{C}$. The dilatometer was heated from room temperature to $500{ }^{\circ} \mathrm{C}$ at a rate of $+20 \mathrm{~K} / \mathrm{min}$, then at $+2 \mathrm{~K} / \mathrm{min}$ to $525{ }^{\circ} \mathrm{C}$ and held for at least $24 \mathrm{~h}$ until the sample diameter does not change anymore.

\section{Results}

\subsection{Volume densification}

The density of N-BK7 glass compressed from PC at $0.5 \mathrm{GPa}$ to $1.5 \mathrm{GPa}$ and $700{ }^{\circ} \mathrm{C}\left(1.25 T_{g}\right)$ was found to increase approximately linearly with pressure in our preceding study ${ }^{22}$ as illustrated in Figure 1(a) (squares). The measured densities of N-BK7 glass after hot compression from PP and GPC are compared with the results from PC in Fig. 1(a). The compile densities of N-BK7 glass, which is pressure quenched from equilibrium states $\left(700{ }^{\circ} \mathrm{C}\right.$ for a holding time longer than $2 \mathrm{~h}$ ) in three different machines, show a linear function of the pressure from $0.1 \mathrm{GPa}$ to $2 \mathrm{GPa}$,

$$
\rho=0.0662 P+2.5026,
$$

where $\rho$ is the density of samples after hot compression in $\mathrm{g} / \mathrm{cm}^{3}$ and $P$ is the applied pressure in GPa. Despite the difference in pressure medium for the hot compression treatments, viz., argon gas in PP (0.1-0.3 GPa), NaCl salt in PC (0.5-1.5 GPa), and nitrogen in GPC (1-2 GPa), the density of N-BK7 glass increases with increasing pressure at around the same rate of $2.6 \% / \mathrm{GPa}$. However, all the samples hot compressed in GPC at various temperatures near the glass transition region for $0.5 \mathrm{~h}$ are 
slightly off the linear relation, indicating that those samples were pressure quenched from nonequilibrium states. Figure 1(b) shows a non-linear increasing trend of the glass density with the dwell temperature at both $1 \mathrm{GPa}$ and $2 \mathrm{GPa}$ for GPC, which is different from the results at ambient pressure, with the latter showing no increase in density with temperature.

\subsection{Volume relaxation}

The length change of hot compressed samples was measured by dilatometer at $525{ }^{\circ} \mathrm{C}\left(0.94 T_{\mathrm{g}}\right)$ and converted to a volume change following

$$
V_{\text {spec }}=\frac{\left(1+\Delta L / L_{0}\right)^{3}}{\rho_{0}}
$$

where $V_{\text {spec }}$ is the specific volume, $\Delta L / L_{0}$ is the length change, and $\rho_{0}$ is the density of the hot compressed glass. The volume recovery of samples hot compressed up to $2 \mathrm{GPa}$ and pressure quenched from equilibrium states in three different methods are reported in Figure 2(a). Moreover, dwell temperature also influences the volume recovery of glass for results from GPC as shown in Figure 3(a) and Figure 4(a).

In our previous study, a two-internal-parameter relaxation model ${ }^{22}$ was developed based on Gupta's approach ${ }^{24}$ and the Tool-Narayanaswamy model25, 26, in which the volume relaxation depends on both fictive temperature $\left(T_{f}\right)^{25}$ and fictive pressure $\left(P_{f}\right)^{24}$ to account for both thermal and pressure history. This model assumes a true isostatic pressure during the hot compression in $\mathrm{PC}^{22}$ and the configurational expansion coefficient ${ }^{24}$ is the key parameter to govern the change in $P_{f}$. The specific volume depends on $T, T_{f}, P$, and $P_{f}$ according to

$$
V=V_{r e f} \exp \left[J_{f r o z}\left(P_{r e f}-P\right)+\Delta J\left(P_{r e f}-P_{f}\right)+3 \alpha_{f r o z}\left(T-T_{r e f}\right)+3 \Delta \alpha\left(T_{f}-T_{r e f}\right)\right],
$$

where $T_{r e f}=525{ }^{\circ} \mathrm{C}, P_{r e f}=0.0001 \mathrm{GPa}, V_{r e f}=0.4065 \mathrm{~cm}^{3} / \mathrm{g}$ (fully recovered specific volume), and $\Delta J=J_{l i q}-J_{f r o z}$ is the difference in compressibility between liquid glass and frozen glass with $J=1 / K\left(K_{\text {liq }}\right.$ is the bulk modulus of liquid glass which is a free parameter and $\left.K_{\text {froz }}=46.5 \mathrm{GPa}\right)$. The derivation of $T_{f}$ and $P_{f}$ are taken from the rates equation in Gupta's approach ${ }^{24}$ together with an efficient and stable algorithm from Markovsky and Soules ${ }^{33}$. The assumptions $L_{T T}=\frac{T}{\Delta C \tau_{c}}, L_{T P}=L_{P T}$ $=\frac{1}{V \Delta \alpha \tau_{\alpha}}$, and $L_{P P}=\frac{1}{V \Delta J \tau_{J}}$ are used for the four kinetic coefficients in Gupta's rates equation ${ }^{24} . \Delta C=$ 
$C_{l i q}-C_{f r o z}$ is the specific heat capacity of the liquid (equilibrium) state $C_{l i q}$ and the frozen (glassy) state $C_{f r o z}$, and similarly, $\Delta \alpha=\alpha_{l i q}-\alpha_{\text {froz }}$ is the difference in thermal expansion coefficient between liquid and frozen glass. This assumption introduces another three free parameters, $f_{c}, f_{\alpha}$, and $f_{J}$, which account for the different factors for the characteristic relaxation time $\left(\tau_{G}\right)$ change in the shear modulus by specific heat $\left(\tau_{c}=f_{c} \tau_{G}\right)$, thermal expansion coefficient $\left(\tau_{\alpha}=f_{\alpha} \tau_{G}\right)$, and compressibility $\left(\tau_{J}=f_{J} \tau_{G}\right)$, respectively. The characteristic relaxation time can be calculated as

$$
\tau_{G}=\tau_{r e f} \exp \left\{\frac{x}{T}\left[\frac{\Delta H}{R}+\frac{\Delta V_{a}}{R}\left(P-P_{r e f}\right)\right]+\frac{1-x}{T_{f}}\left[\frac{\Delta H}{R}+\frac{\Delta V_{a}}{R}\left(P_{f}-P_{r e f}\right)\right]-\frac{\Delta H}{R T_{r e f}}\right\},
$$

where $\Delta H$ is the activation enthalpy, $R$ is the gas constant $(\Delta H / R=74000 \mathrm{~K}), x$ is a fixed factor in Tool-Narayanaswamy model ${ }^{25,26}$ ( $x=0.7$ for N-BK7 glass), $\Delta V_{a}$ is the activation volume ${ }^{34}$ and $\tau_{r e f}=0.45 \mathrm{~h}$. Thus, the model has five free parameters: $K_{\mathrm{liq}}, f_{c}, f_{\alpha}, f_{J}$ and $\Delta V_{a}$. In the case that no pressure is applied in the experiments, this model reduces to the original Tool-Narayanaswamy model ${ }^{25,26}$.

As shown in Figures 2(a), 3(a), and 4(a), the two-internal-parameter relaxation model ${ }^{22}$ captures both the influence of the pressure history and thermal history on the volume recovery of N-BK7 glass at $525{ }^{\circ} \mathrm{C}$ with a single set of parameters (see figure caption in Figure 2(a)). The best-fit parameters were detected by fitting all the data in the three figures simultaneously using a multidimensional unconstrained nonlinear minimization optimization algorithm (i.e., the Nelder-Mead Simplex search algorithm as incorporated in the MATLAB function fminsearch ${ }^{35}$ ). The initial cooling, the high pressure treatment (if any), the heating-up stage, and finally, the isothermal volume recovery measurement are all considered with the two-internal-parameter relaxation model. To check the evolution of the internal parameters, the corresponding changes of $T_{\mathrm{f}}$ and $P_{\mathrm{f}}$ of samples versus time are given in Figure 2(b). The results indicate that $T_{\mathrm{f}}$ increases with the increasing applied pressure. The crossover phenomenon ${ }^{36}$ is also detected in the evolution of $T_{\mathrm{f}}$. The value of $P_{\mathrm{f}}$ is initially equal to the applied pressure during hot compression but gradually decreases to ambient pressure when the volume is fully recovered. Moreover, both $T_{\mathrm{f}}$ and $\tau_{G}$ at the beginning of the relaxation process (values are reported in Table 1) increase approximately linearly with fictive pressure, consistent with our previous investigations. ${ }^{22}$ The increase of $\tau_{G}$ at higher pressures indicates that samples compressed at higher pressure require longer times to relax towards a new equilibrium in the glass transition region.

This article is protected by copyright. All rights reserved 
Figure 3(a) shows the volume recovery of samples at $525^{\circ} \mathrm{C}$ and $1 \mathrm{~atm}$ fitted by the two-internalparameter relaxation model with the same set of fitting parameters as in Figure 2(a). Prior to relaxation, the glass samples were hot compressed in GPC at $1 \mathrm{GPa}$ and various dwell temperatures $\left(560{ }^{\circ} \mathrm{C}, 580^{\circ} \mathrm{C}\right.$ and $600{ }^{\circ} \mathrm{C}$ ) for $0.5 \mathrm{~h}$. The model captures the volume relaxation of samples quenched from $580{ }^{\circ} \mathrm{C}$ and $600{ }^{\circ} \mathrm{C}$ for $0.5 \mathrm{~h}$ under $1 \mathrm{GPa}$, while it does not reproduce well the sample quenched from $560{ }^{\circ} \mathrm{C}$ for $0.5 \mathrm{~h}$. The corresponding changes in $T_{\mathrm{f}}$ and $P_{\mathrm{f}}$ with time are shown in Figure 3(b) as well as in Table 1 where the strong coupling of temperature and pressure histories in the two-internalparameter relaxation model can be observed. The $T_{\mathrm{f}}$ of the sample pressure quenched from $600{ }^{\circ} \mathrm{C}$ for $0.5 \mathrm{~h}$ at the beginning of relaxation at $525^{\circ} \mathrm{C}$ and $1 \mathrm{~atm}$ is slightly $\left(3.4^{\circ} \mathrm{C}\right)$ lower than the $T_{\mathrm{f}}$ of the sample pressure quenched from equilibrium state under $1 \mathrm{GPa}$ equals to $571.5^{\circ} \mathrm{C}$, which in turn is slightly higher $\left(2.1^{\circ} \mathrm{C}\right)$ than the one pressure quenched from $580{ }^{\circ} \mathrm{C}$. On the other hand, the $T_{\mathrm{f}}$ of the sample pressure quenched from $560{ }^{\circ} \mathrm{C}$ for $0.5 \mathrm{~h}$ under $1 \mathrm{GPa}$ is $18.1^{\circ} \mathrm{C}$ lower than that of the $600{ }^{\circ} \mathrm{C}$ sample. More interestingly, the $P_{\mathrm{f}}$ of the sample pressure quenched from $560{ }^{\circ} \mathrm{C}$ for $0.5 \mathrm{~h}$ under $1 \mathrm{GPa}$ is only $0.4 \mathrm{GPa}$, which is much lower than the samples quenched from $580{ }^{\circ} \mathrm{C}$ and $600{ }^{\circ} \mathrm{C}$ around 0.9 GPa. To conclude, samples quenched from $1 \mathrm{GPa}$ in nonequilibrium states have lower $T_{\mathrm{f}}$ and $P_{\mathrm{f}}$ compared with the one quenched from $1 \mathrm{GPa}$ after equilibrium was reached.

Figure 4(a) shows the volume recovery of samples at $525^{\circ} \mathrm{C}$ and 1 atm fitted by the two-internalparameter relaxation model with the same set of fitting parameters as in Figure 2(a). Prior to relaxation, the glass samples were hot compressed in GPC at $2 \mathrm{GPa}$ and various dwell temperatures $\left(580^{\circ} \mathrm{C}, 600^{\circ} \mathrm{C}\right.$ and $700{ }^{\circ} \mathrm{C}$ ) for $0.5 \mathrm{~h}$. Overall, the model predicts the influence of dwell temperature on volume relaxation of N-BK7 glass, although the fit is not perfect. The corresponding changes of $T_{\mathrm{f}}$ and $P_{\mathrm{f}}$ with time are presented in Figure 4(b) and Table1, where again the coupling of temperature and pressure histories is significant. The cross-over of $T_{\mathrm{f}}$ is significant in Figure 4(b), which is strongly correlated with $P_{\mathrm{f}}$. The sample quenched from $700{ }^{\circ} \mathrm{C}$ for $0.5 \mathrm{~h}$ under $2 \mathrm{GPa}$ has slightly lower $T_{\mathrm{f}}$ and $P_{\mathrm{f}}$ at the beginning of relaxation compared to samples quenched from $700{ }^{\circ} \mathrm{C}$ for $2 \mathrm{~h}$ under $2 \mathrm{GPa}$. This indicates that the sample has not reached equilibrium during the hot compressing in GPC for $0.5 \mathrm{~h}$. Moreover, the $T_{\mathrm{f}}$ and $P_{\mathrm{f}}$ of samples quenched from $600{ }^{\circ} \mathrm{C}$ for $0.5 \mathrm{~h}$ under $2 \mathrm{GPa}$ at the beginning of relaxation are $20.0{ }^{\circ} \mathrm{C}$ and $0.72 \mathrm{GPa}$ lower, respectively, than those of the sample quenched at $700{ }^{\circ} \mathrm{C}(0.5 \mathrm{~h} / 2 \mathrm{GPa})$, which in turn are significantly higher than the samples quenched at 
$580{ }^{\circ} \mathrm{C}(0.5 \mathrm{~h} / 2 \mathrm{GPa}) . T_{\mathrm{f}}$ of the sample pressure quenched from $580{ }^{\circ} \mathrm{C}$ for $0.5 \mathrm{~h}$ under $2 \mathrm{GPa}$ at the beginning of relaxation is approximately $549.4{ }^{\circ} \mathrm{C}$, which is between the values for samples quenched from equilibrium under $0.3 \mathrm{GPa}$ and $0.5 \mathrm{GPa}$ (see Table 1). The $P_{\mathrm{f}}$ of this sample is only $0.32 \mathrm{GPa}$. The difference in $T_{\mathrm{f}}$ and $P_{\mathrm{f}}$ is even larger for samples quenched from nonequilibrium and equilibrium states at $2 \mathrm{GPa}$.

\section{Discussion}

In the previous study ${ }^{22}$, we restricted the $\Delta V_{a}$ to be equal to the molar volume $\left(\sim 8.13 \mathrm{~cm}^{3} / \mathrm{mol}\right)$ of glass during relaxation at $525{ }^{\circ} \mathrm{C}$ in the two-internal-parameter relaxation model. However, recent rheological research on N-BK7 glass reported a $\Delta V_{a}$ of $\sim 1.4 \mathrm{~cm}^{3} / \mathrm{mol}$ for plastic yielding and $\sim 2.0$ $\mathrm{cm}^{3} / \mathrm{mol}$ for viscous flow, which are lower than the molar volume during relaxation in this study. Moreover, results from tribology $37,38,39$ (Arrhenius-type activation) indicates that the $\Delta V_{a}$ can be either lower or higher than the molar volume. Indeed, studies on metallic and polymer glasses indicate that $\Delta V_{a}$ can go up to $100 \mathrm{~cm}^{3} / \mathrm{mol}^{34}$. Therefore, in this work, the $\Delta V_{a}$ is set to be a free parameter, which allows the $\Delta V_{a}$ to be either lower or higher than the molar volume depending on the experimental data. The $\Delta V_{a}$ is found to be the dominant factor in the fitting of dwell temperature dependence in Figures 3 and 4. The best-fit $\Delta V_{a}$ value is around $28.6 \mathrm{~cm}^{3} / \mathrm{mol}$ during the pressuredependent relaxation process, which is $\sim 3.5$ times of the molar volume. This relatively large $\Delta V_{a}$ reveals the strong coupling of temperature and pressure histories for samples quenched from the nonequilibrium state under high pressure.

Figure 2(b) displays a significant minimum in $T_{\mathrm{f}}$ followed by a crossover back to higher $T_{\mathrm{f}}$ (nonmonotonic decay) while the corresponding $P_{\mathrm{f}}$ decays monotonically with time. A similar crossover phenomenon has been reported in the relaxation of selenium glass from various temperature histories ${ }^{40,41}$ where the nonmonotonic decay is observed both experimentally and computationally (Mauro-Loucks enthalpy landscape model ${ }^{42}$ ) in density and enthalpy fluctuations while the relaxation of enthalpy and density is monotonic. The crossover of $T_{\mathrm{f}}$ in this work could be related with the initial fast relaxation of the number of remaining internal degrees of freedom (floppy modes) in the system that results in a rapid decrease of $P_{\mathrm{f}}$ until most of the faster-relaxing floppy modes have relaxed 
resulting in a minimum for $T_{\mathrm{f}}$. This is followed by a slower long-range relaxation of the remaining floppy modes. ${ }^{42,43,44}$ Moreover, the nonmonotonic decay of $T_{\mathrm{f}}$ is reduced and even disappears upon pressure quenching from nonequilibrium states at 1 and $2 \mathrm{GPa}$ (Figures 3(b) and 4(b)) due to the relative lower $P_{\mathrm{f}}$ than the those of the samples pressure quenched from equilibrium states.

The model indicates that hot compression experiments on N-BK7 glass at $T_{g}$ to $1.07 T_{g}$ for $0.5 \mathrm{~h}$ under $1 \mathrm{GPa}$ and at $1.03 T_{g}$ to $1.25 T_{g}$ for $0.5 \mathrm{~h}$ under $2 \mathrm{GPa}$ do not reach the equilibrium states. This can be verified by our recent study ${ }^{45}$ on the atomic structure of hot compressed borosilicate glass. The recent results from ${ }^{11} \mathrm{~B}$ solid-state nuclear magnetic resonance (NMR) spectroscopy shows that the fraction of four coordinated boron increases with increasing of isothermal holding (annealing) temperature for the N-BK7 samples hot compressed from the same conditions (except for the $1 \mathrm{GPa}$ samples which is nearly reach the equilibrium state).

We note that the set of best-fit parameters for the two-internal-parameter relaxation model is not unique and some of the best fittings are not perfect (especially in Figure 4(a)). This is due to limitations of the applied multidimensional unconstrained nonlinear minimization optimization algorithm and the measurement uncertainty of the experimental results. We further tested the twointernal-parameter relaxation model by introducing a weighting factor to discriminate silicate from the other compositions following Narayanaswamy's approach ${ }^{26}$. However, the fitting is not significantly improved due to the limitation of the experimental measurement uncertainty. Nevertheless, the new best-fit $K_{\text {liq }}$ value is equal to $18 \mathrm{GPa}$, which is closer to the rule of thumb estimation of $15.5 \mathrm{GPa}$ (e.g., one-third of the bulk modulus of the solid glass) than the previous ${ }^{22}$ fitting result. In summary, the two-internal-parameter relaxation model can generally reproduce the pressure dependence of volume relaxation of N-BK7 glass pressure quenched from nonequilibrium state. This model also provides reference experimental parameters for the isostatic hot compression on N-BK7 glass and could be applied to other glass compositions by adjusting the corresponding composition-temperature-pressure parameters.

\section{Conclusion}

In this study, we found that the density of N-BK7 glass, pressure quenched from the equilibrium state in three different machines, increases approximately linear with increasing pressure up to $2 \mathrm{GPa}$. 
Together with the volume recovery results, we assert that the preceding high pressure treatment in PC (uniaxial loading) generated a similar isostatic pressure effect on N-BK7 glass as in PP and in GPC. Moreover, the previously proposed two-internal-parameter relaxation model incorporates a new set of free parameters can reasonably address the pressure and temperature dependence of relaxation of glass even for the samples pressure quenched from nonequilibrium states. Also, the model indicates that hot compression experiments on N-BK7 glass at $600{ }^{\circ} \mathrm{C}\left(\sim 1.07 T_{g}\right)$ for $0.5 \mathrm{~h}$ under $1 \mathrm{GPa}$ and at $700{ }^{\circ} \mathrm{C}\left(\sim 1.25 T_{g}\right)$ for $0.5 \mathrm{~h}$ under $2 \mathrm{GPa}$ does not reach the equilibrium states. The model can be used for predicting the volume relaxation of N-BK7 glass under various pressure and temperature histories and also has the potential to apply to other glass compositions.

\section{Acknowledgments}

Linfeng Ding is funded by the Deutsche Forschungsgemeinschaft (DFG) through a DFG Fellowship (GZ: DI 2545). Kuo-Hao Lee is funded by SCHOTT AG, Mainz, Germany. Linfeng Ding appreciates the valuable comments and great support from Dr. Clemens Kunisch, Dr. Seong H. Kim and Dr. Boris Kaus. The authors thank the technicians and engineers at the SCHOTT machine shop for the sample preparation. This study was partially funded by the European Union's Horizon 2020 research and innovation program under the Marie Sklodowska-Curie Grant Agreement No. 642029.

\section{References}

1. Ruocco G. Glasses when disorder helps. Nat Mater. 2008;7:842-43.

2. Wondraczek L, Mauro JC. Advancing glasses through fundamental research. J Eur Ceram Soc. 2009;29:1227-34.

3. Scherer GW. Theories of Relaxation. J Non-Cryst Solids. 1990;123:75-89.

4. Zheng QJ, Mauro JC. Viscosity of glass-forming systems. J Am Ceram Soc. 2017;100:6-25.

5. Lee SK, Mibe K, Fei Y, Cody GD, Mysen BO. Structure of $\mathrm{B}_{2} \mathrm{O}_{3}$ Glass at High Pressure: A B11 Solid-State NMR Study. Phys Rev Lett. 2005;94:165507.

6. Wang Y, Sakamaki T, Skinner LB, Jing Z, Yu T, Kono Y, et al. Atomistic insight into viscosity and density of silicate melts under pressure. Nat Commun. 2014;5:3241.

This article is protected by copyright. All rights reserved 
7. Mysen BO, Virgo D, Seifert FA. The structure of silicate melts: implications for chemical and physical properties of natural magma. Rev Geophys. 1982;20:353-83.

8. Østergaard MB, Youngman RE, Svenson MN, Rzoska SJ, Bockowski M, Jensen LR, et al. Temperature-dependent densification of sodium borosilicate glass. RSC Advances. 2015;5:78845-51.

9. Svenson MN, Bechgaard TK, Fuglsang SD, Pedersen RH, Tjell AØ, Østergaard MB, et al. Composition-Structure-Property Relations of Compressed Borosilicate Glasses. Phys Rev Appl. 2014;2:024006.

10. Wondraczek L, Behrens H, Yue YZ, Deubener J, Scherer GW. Relaxation and glass transition in an isostatically compressed diopside glass. J Am Ceram Soc. 2007;90:1556-61.

11. Svenson MN, Thirion LM, Youngman RE, Mauro JC, Rzoska SJ, Bockowski M, et al. PressureInduced Changes in Interdiffusivity and Compressive Stress in Chemically Strengthened Glass. ACS Appl Mater Interfaces. 2014;6:10436-44.

12. Smedskjaer MM, Youngman RE, Striepe S, Potuzak M, Bauer U, Deubener J, et al. Irreversibility of pressure induced boron speciation change in glass. Sci Rep. 2014;4:1-6.

13. Höfler S, Seifert F. Volume relaxation of compacted $\mathrm{SiO}_{2}$ glass: a model for the conservation of natural diaplectic glasses. Earth and planetary science letters. 1984;67:433-38.

14. Wondraczek L, Krolikowski S, Behrens H. Kinetics of pressure relaxation in a compressed alkali borosilicate glass. J Non-Cryst Solids. 2010;356:1859-62.

15. Guerette M, Ackerson MR, Thomas J, Yuan F, Watson EB, Walker D, et al. Structure and properties of silica glass densified in cold compression and hot compression. Sci Rep. 2015;5:15343.

16. Paterson MS. A High-Pressure, High-Temperature Apparatus for Rock Deformation. Int J Rock Mech Min Sci. 1970;7:517-26.

17. Boyd FR, England JL. Apparatus for Phase-Equilibrium Measurements at Pressures up to 50Kilobars and Temperatures up to 1750-Degrees-C. J Geophys Res. 1960;65:741-48.

18. Li BS, Jackson I, Gasparik T, Liebermann RC. Elastic wave velocity measurement in multi-anvil apparatus to $10 \mathrm{GPa}$ using ultrasonic interferometry. Phys Earth Planet Inter. 1996;98:79-91.

This article is protected by copyright. All rights reserved 
19. Svenson MN, Bechgaard TK, Fuglsang SD, Pedersen RH, Tjell AO, Ostergaard MB, et al. Composition-Structure-Property Relations of Compressed Borosilicate Glasses. Phys Rev Appl. 2014;2.

20. Smedskjaer MM, Bauchy M, Mauro JC, Rzoska SJ, Bockowski M. Unique effects of thermal and pressure histories on glass hardness: Structural and topological origin. J Chem Phys. 2015;143.

21. Wu J, Gross TM, Huang L, Jaccani SP, Youngman RE, Rzoska SJ, et al. Composition and pressure effects on the structure, elastic properties and hardness of aluminoborosilicate glass. $\mathrm{J}$ Non-Cryst Solids. 2020;530:119797.

22. Ding L, Buhre S, Kunisch C, Kaus B. Pressure dependence of density and structural relaxation of glass near the glass transition region. J Am Ceram Soc. 2018;101:1149-58.

23. Ding L, Thieme M, Demouchy S, Kunisch C, Kaus BJP. Effect of pressure and temperature on viscosity of a borosilicate glass. J Am Ceram Soc. 2018;101:3936-46.

24. Gupta PK. Fictive Pressure Effects in Structural Relaxation. J Non-Cryst Solids. 1988;102:231-39.

25. Tool AQ. Relation between inelastic deformability and thermal expansion of glass in its annealing range. J Am Ceram Soc. 1946;29:240-53.

26. Narayanaswamy OS. A Model of Structural Relaxation in Glass. J Am Ceram Soc. 1971;54:49198.

27. Mosaddegh P, Ziegert JC. Friction measurement in precision glass molding: An experimental study. J Non-Cryst Solids. 2011;357:3221-25.

28. Dyer PE, Maswadi SM, Walton CD, Ersoz M, Fletcher PDI, Paunov VN. 157-nm laser micromachining of N-BK7 glass and replication for microcontact printing. Appl Phys A. 2003;77:391-94.

29. Koontz E, Blouin V, Wachtel P, Musgraves JD, Richardson K. Prony Series Spectra of Structural Relaxation in N-BK7 for Finite Element Modeling. J Phys Chem A. 2012;116:12198-205.

30. An QL, Ming WW, Chen M. Experimental Investigation on Cutting Characteristics in Nanometric Plunge-Cutting of BK7 and Fused Silica Glasses. Materials. 2015;8:1428-41.

31. Lee K-H, Yang Y, Ziebarth B, Mannstadt W, Davis MJ, Mauro JC. Evaluation of classical interatomic potentials for molecular dynamics simulations of borosilicate glasses. J Non-Cryst Solids. 2020;528:119736.

This article is protected by copyright. All rights reserved 
32. Ziaja K, Foley SF, White RW, Buhre S. Metamorphism and melting of picritic crust in the early Earth. Lithos. 2014;189:173-84.

33. Markovsky A, Soules TF. An Efficient and Stable Algorithm for Calculating Fictive Temperatures. J Am Ceram Soc. 1984;67:C56-C57.

34. Jin HJ, Gu XJ, Wen P, Wang LB, Lu K. Pressure effect on the structural relaxation and glass transition in metallic glasses. Acta Materialia. 2003;51:6219-31.

35. Lagarias JC, Reeds JA, Wright MH, Wright PE. Convergence properties of the Nelder-Mead simplex method in low dimensions. SIAM J Optim. 1998;9:112-47.

36. Ritland HN. Density phenomena in the transformation range of a borosilicate crown glass. J Am Ceram Soc. 1954;37:370-77.

37. He X, Kim SH. Mechanochemistry of physisorbed molecules at tribological interfaces: molecular structure dependence of tribochemical polymerization. Langmuir. 2017;33:2717-24.

38. Felts JR, Oyer AJ, Hernández SC, Whitener Jr KE, Robinson JT, Walton SG, et al. Direct mechanochemical cleavage of functional groups from graphene. Nat Commun. 2015;6:1-7.

39. Jacobs TD, Carpick RW. Nanoscale wear as a stress-assisted chemical reaction. Nat Nanotechnol. 2013;8:108-12.

40. Mauro JC, Uzun SS, Bras W, Sen S. Nonmonotonic evolution of density fluctuations during glass relaxation. Phys Rev Lett. 2009;102:155506.

41. Mauro JC. Effect of fragility on relaxation of density fluctuations in glass. J Non-Cryst Solids. 2011;357:3520-23.

42. Mauro JC, Loucks RJ. Selenium glass transition: A model based on the enthalpy landscape approach and nonequilibrium statistical mechanics. Physical Review B. 2007;76.

43. Phillips J. Stretched exponential relaxation in molecular and electronic glasses. Rep Prog Phys. 1996;59:1133.

44. Song W, Li X, Wang B, Anoop Krishnan N, Goyal S, Smedskjaer MM, et al. Atomic picture of structural relaxation in silicate glasses. Appl Phys Lett. 2019;114:233703.

45. Ding L, Lee KH, Zhao T, Yang Y, Bockowski M, Ziebarth B, et al. Atomic Structure of Hot Compressed Borosilicate Glasses. J Am Ceram Soc. https://doi.org/10.1111/jace.17377

This article is protected by copyright. All rights reserved 


\section{Table captions}

Table 1 Changes in $T_{\mathrm{f}}, P_{\mathrm{f}}$ and $\tau_{G}$ at the beginning of volume recovery at $525{ }^{\circ} \mathrm{C}$ and 1 atm in the model.

\section{Figure captions}

Figure 1 (a) Pressure dependence of density of hot compressed glass samples from three different experimental methods (PP, PC, GPC) (b) Temperature dependence of density of hot compressed samples at $1 \mathrm{~atm}, 1 \mathrm{GPa}$ and $2 \mathrm{GPa}$ from GPC. The dashed lines represent the exponential decay function fits.

Figure 2 (a) Isothermal volume recovery of glasses at $525{ }^{\circ} \mathrm{C}$ and 1 atm fitted by the two-internalparameter relaxation model with $K_{\text {liq }}=18 \mathrm{GPa}, f_{\mathrm{c}}=3, f_{\mathrm{J}}=4, f_{\mathrm{\alpha}}=39, \Delta V_{\mathrm{a}}=28.6 \mathrm{~cm}^{3} / \mathrm{mol}$. Prior to relaxation, the glass samples have been hot compressed up to $2 \mathrm{GPa}$ and pressure quenched from equilibrium states (at $700{ }^{\circ} \mathrm{C}$ for a holding time of longer than $2 \mathrm{~h}$ ) in three different methods and compared with an uncompressed sample. Error bars represent the uncertainty of the final fully recovered specific volume at $525{ }^{\circ} \mathrm{C}$. (b) Corresponding change of $T_{\mathrm{f}}$ and $P_{\mathrm{f}}$ versus time as predicted by the two-internal-parameter relaxation model.

Figure 3 (a) Isothermal volume recovery of glass at $525{ }^{\circ} \mathrm{C}$ and 1 atm fitted by the two-internalparameter relaxation model with the same set of fitting parameters as in Figure 2(a). Prior to relaxation, the glass samples were hot compressed in GPC at $1 \mathrm{GPa}$ and various dwell temperatures for $0.5 \mathrm{~h}$. Error bars represent the uncertainty of final fully recovered specific volume at $525{ }^{\circ} \mathrm{C}$. (b) Corresponding change of $T_{\mathrm{f}}$ and $P_{\mathrm{f}}$ of samples versus time as predicted by the two-internal-parameter relaxation model.

Figure 4 (a) Isothermal volume recovery of glass at $525{ }^{\circ} \mathrm{C}$ and 1 atm fitted by the two-internalparameter relaxation model with the same set of fitting parameters as in Figure 2. Prior to relaxation, the glass samples were hot compressed in GPC at $2 \mathrm{GPa}$ and various dwell temperatures for $0.5 \mathrm{~h}$. Error bars represent the uncertainty of final fully recovered specific volume at $525{ }^{\circ} \mathrm{C}$. (b) Corresponding change of $T_{\mathrm{f}}$ and $P_{\mathrm{f}}$ of samples versus time as predicted by the two-internal-parameter relaxation model.

This article is protected by copyright. All rights reserved 
Table 1 Changes in $T_{\mathrm{f}}, P_{\mathrm{f}}$ and $\tau_{G}$ at the beginning of volume recovery at $525^{\circ} \mathrm{C}$ and $1 \mathrm{~atm}$ in the model.

\begin{tabular}{|c|c|c|c|c|}
\hline Sample & P \& T histories & $\begin{array}{c}T_{\mathrm{f}} \\
{\left[{ }^{\circ} \mathrm{C}\right]}\end{array}$ & $\begin{array}{c}P_{\mathrm{f}} \\
{[\mathrm{GPa}]}\end{array}$ & $\begin{array}{c}\tau_{G} \\
{[\mathrm{~h}]}\end{array}$ \\
\hline $1 \mathrm{~atm}$ & $1 \mathrm{~atm} / 560{ }^{\circ} \mathrm{C} / 2 \mathrm{~h}$ & 534.3 & -0.01 & 0.16 \\
\hline PP-1 & $0.1 \mathrm{GPa} / 700^{\circ} \mathrm{C} / 2 \mathrm{~h}$ & 542.2 & 0.08 & 0.28 \\
\hline PP-2 & $0.2 \mathrm{GPa} / 700^{\circ} \mathrm{C} / 2 \mathrm{~h}$ & 545.5 & 0.18 & 0.28 \\
\hline PP-3 & $0.3 \mathrm{GPa} / 700^{\circ} \mathrm{C} / 2 \mathrm{~h}$ & 548.7 & 0.27 & 0.28 \\
\hline PC-1 & $0.5 \mathrm{GPa} / 700^{\circ} \mathrm{C} / 24 \mathrm{~h}$ & 555.2 & 0.45 & 0.29 \\
\hline PC-2 & $0.75 \mathrm{GPa} / 700^{\circ} \mathrm{C} / 24 \mathrm{~h}$ & 563.3 & 0.69 & 0.29 \\
\hline GPC-1 & $1 \mathrm{GPa} / 700^{\circ} \mathrm{C} / 2 \mathrm{~h}$ & 571.5 & 0.92 & 0.30 \\
\hline PC-3 & $1.5 \mathrm{GPa} / 700^{\circ} \mathrm{C} / 24 \mathrm{~h}$ & 587.8 & 1.39 & 0.31 \\
\hline GPC-2 & $2 \mathrm{GPa} / 700^{\circ} \mathrm{C} / 2 \mathrm{~h}$ & 604.1 & 1.86 & 0.32 \\
\hline GPC-3 & $1 \mathrm{GPa} / 560^{\circ} \mathrm{C} / 0.5 \mathrm{~h}$ & 550.0 & 0.40 & 0.28 \\
\hline GPC-4 & $1 \mathrm{GPa} / 580^{\circ} \mathrm{C} / 0.5 \mathrm{~h}$ & 566.0 & 0.87 & 0.30 \\
\hline GPC-5 & $1 \mathrm{GPa} / 600^{\circ} \mathrm{C} / 0.5 \mathrm{~h}$ & 568.1 & 0.91 & 0.29 \\
\hline GPC-6 & $2 \mathrm{GPa} / 580^{\circ} \mathrm{C} / 0.5 \mathrm{~h}$ & 549.4 & 0.32 & 0.25 \\
\hline GPC-7 & $2 \mathrm{GPa} / 600^{\circ} \mathrm{C} / 0.5 \mathrm{~h}$ & 580.2 & 1.12 & 0.25 \\
\hline GPC-8 & $2 \mathrm{GPa} / 700^{\circ} \mathrm{C} / 0.5 \mathrm{~h}$ & 600.2 & 1.84 & 0.33 \\
\hline
\end{tabular}

This article is protected by copyright. All rights reserved 
(a)

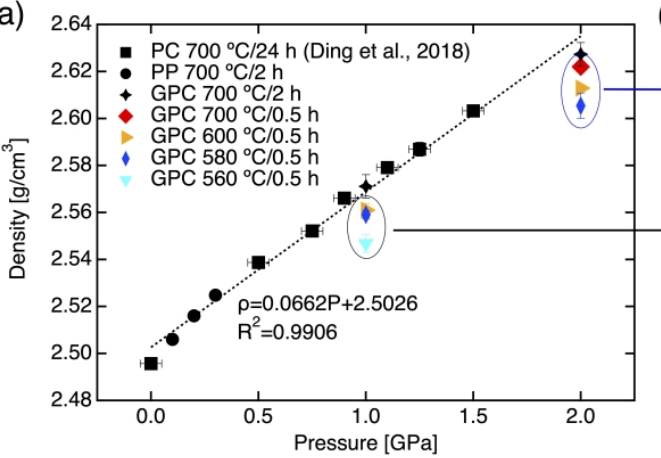

(b)

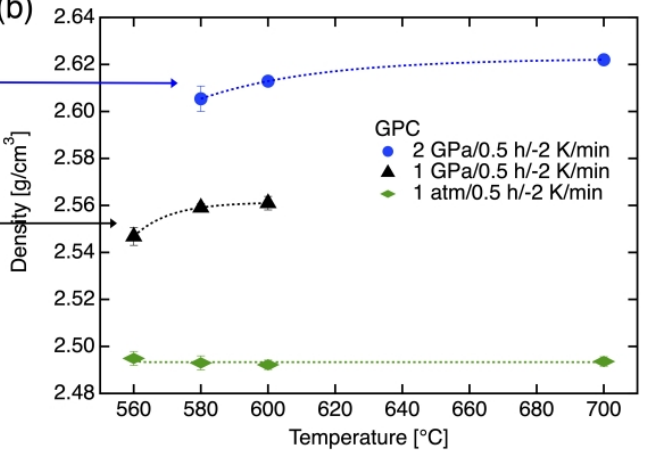

jace_17482_f1.jpg 

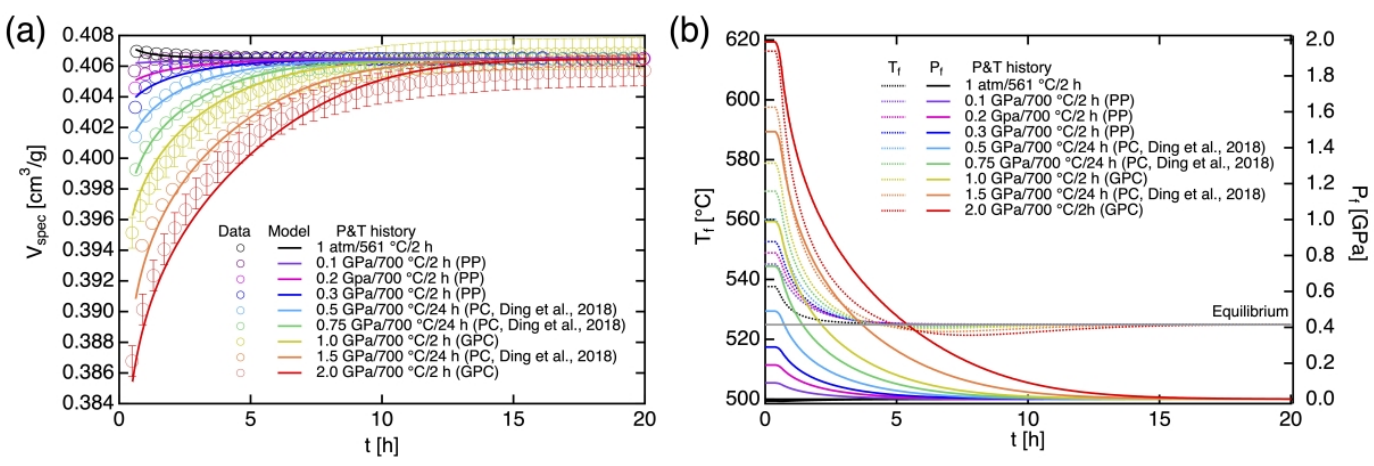

jace_17482_f2.jpg

This article is protected by copyright. All rights reserved 

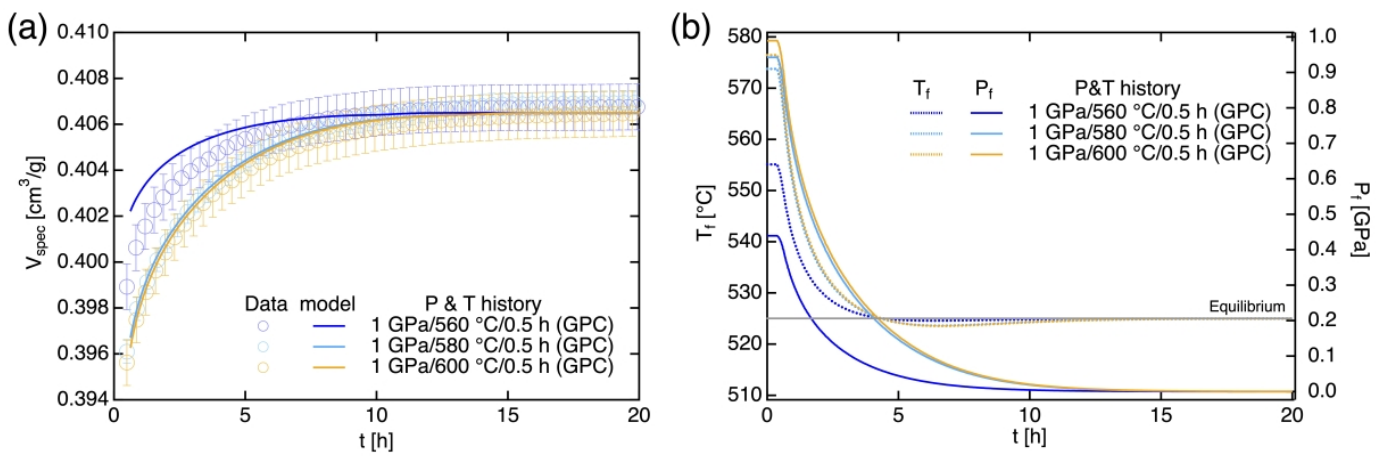

jace_17482_f3.jpg

This article is protected by copyright. All rights reserved 

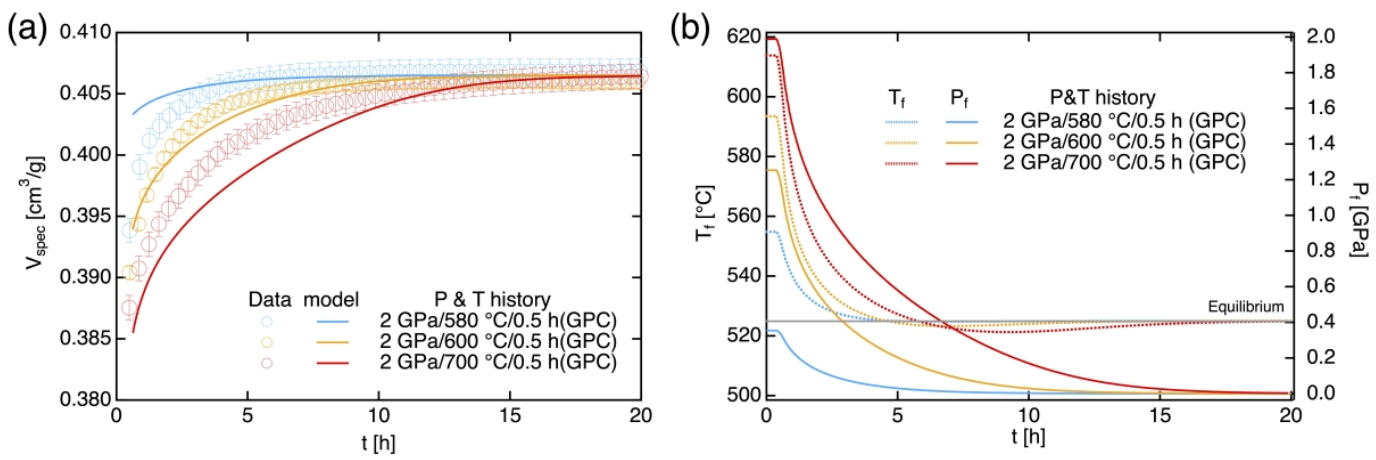

jace_17482_f4.jpg 